\title{
Aetiology and prognostic factors of patients with AIDS presenting life-threatening acute respiratory failure
}

\author{
A. Torres, M. El-Ebiary, R. Marrades, J-M. Miró, J-M. Gatell, J.M. Sanchez-Nieto, \\ A. Xaubet, C. Agustí, R. Rodriguez-Roisin
}

Aetiology and prognostic factors of patients with AIDS presenting life-threatening acute respiratory failure. A. Torres, M. El-Ebiary, R. Marrades, J-M. Miró, J-M. Gatell, J.M. Sanchez-Nieto, A. Xaubet, C. Agustí, R. Rodriguez-Roisin. @ERS Journals Ltd 1995.

ABSTRACT: Respiratory failure is a significant contributor to morbidity and mortality in patients with the acquired immune deficiency syndrome (AIDS). We performed a study to investigate the aetiology, prognostic factors, and short- and long-term outcome of AIDS patients with life-threatening respiratory failure and pulmonary infiltrates.

Forty-two AIDS patients (29 of whom required mechanical ventilation), admitted to a Respiratory Intensive Care Unit (ICU) from 1985 to 1992 because of severe respiratory failure (arterial oxygen tension/fractional inspiratory oxygen $\left(P_{\mathrm{a}}, \mathrm{O}_{2} / F \mathbf{I}, \mathrm{O}_{2}\right)$ ratio at hospital admission $19 \pm 14 \mathrm{kPa}($ mean $\pm \mathrm{sD}))$ and diffuse pulmonary infiltrates, were studied for evaluation of the aetiology and outcome. Necropsy studies were performed in 14 out of $23(61 \%)$ patients who died.

Pneumocystis carinii was the most common aetiology of pulmonary infiltrates (28 patients $(67 \%))$. Overall, 19 patients survived $(45 \%)$ and $23(55 \%)$ died. A multivariate analysis of prognostic factors influencing the outcome of the whole population showed that the presence of $P$. carinii pneumonia and the requirement for mechanical ventilation (MV) were the major determinants of outcome for this type of patient. The median survival time after ICU discharge for $P$. carinii pneumonia patients was lower (49 days) when compared to that of the remaining patients (154 days). Median survival time after ICU discharge for patients needing MV (112 days) did not differ from that observed in patients not requiring artificial ventilatory support (154 days).

Although the ICU survival rate in this study was reasonable, $55 \%$ for the whole population, and $36 \%$ for $P$. carinii pneumonia patients, the poor outcome after ICU discharge, in particular for $P$. carinii pneumonia patients, deserves the reassessment of ICU admission criteria for this type of AIDS population.

Eur Respir J., 1995, 8, 1922-1928.
Serveis de Pneumologia i Al.lèrgia Respiratòria and Malalties Infeccioses, Hospital Clínic, Departament de Medicina, Universitat de Barcelona, Spain.

Correspondence: A. Torres

Servei de Pneumologia

Hospital Clínic

Villarroel 170

08036 Barcelona

Spain

Keywords:

Acquired immune deficiency syndrome aetiology

Pneumocystis carinii pneumonia

pneumonia

prognosis

respiratory failure

Received: March 101995

Accepted after revision August 161995

Supported by Grants 92/0415 and 93/0164 from the Fondo de Investigación Sanitaria de la Seguridad Social (FIS), and Comissió Interdepartamental per a la Recerca i Tecnologia (CIRIT).
Acute respiratory failure is a frequent complication during the evolution of acquired immune deficiency syndrome (AIDS) patients [1]. For this reason, they may require intensive care unit (ICU) admission. Pneumocystis carinii pneumonia (PCP) is the most frequent aetiology of respiratory failure that develops in approximately $60-80 \%$ of patients with AIDS [1,2]. Although respiratory failure due to PCP has decreased because of prophylactic measures, other infectious aetiologies, such as tuberculosis, cytomegalovirus, bacteria and fungi, represent an increasing cause of severe acute respiratory failure [2].

Data regarding mortality of AIDS patients with severe respiratory failure are only known when considering PCP. Mortality of severe PCP is around 60\% [3, 4]. Prognostic factors of outcome for this subset of the population have been investigated in some clinical studies [5-8]. Established predictors of acute and long-term survival of patients with AIDS and PCP have been based on information obtained at the initial clinical presentation [7]. Among these predictors are alveolar-arterial oxygen tension gradient $\left(\mathrm{A}-\mathrm{a} P \mathrm{O}_{2}\right)$, Acute Physiology and Chronic Health Evaluation (APACHE) score, severity of chest radiographic abnormalities, and lactate dehydrogenase (LDH) serum levels [5-8]. A recent study by WACHTER et al. [9] using stepwise logistic regression demonstrated that ICU admission era (after 1985) and albumin levels were the only variables associated with survival of AIDS patients with PCP admitted to an ICU.

We performed this study to investigate the aetiology and prognostic factors of outcome of AIDS patients with severe respiratory failure admitted to a respiratory ICU. Specifically, we compared PCP with other infectious aetiologies. Necropsy studies were performed in 14 out of $23(61 \%)$ of the nonsurvivors. 


\section{Material and methods}

\section{Patients}

Forty two AIDS patients with bilateral pulmonary infiltrates and severe acute respiratory failure were admitted to the Respiratory Intensive Care Unit of the Hospital Clínic of Barcelona between 1985 and 1992. All patients accomplished all of the following criteria of admission to the ICU: 1$)$ presence of severe acute respiratory failure (arterial oxygen tension $\left(P \mathrm{a}, \mathrm{O}_{2}\right)<7 \mathrm{kPa}$ breathing room air or $\mathrm{Pa}, \mathrm{O}_{2} /$ inspiratory oxygen fraction $\left(F \mathrm{I}, \mathrm{O}_{2}\right)$ ratio $\left.\left.<33 \mathrm{kPa}\right) ; 2\right)$ respiratory rate higher than 30 breaths. $\mathrm{min}^{-1}$; and 3) bilateral pulmonary infiltrates. AIDS patients were diagnosed based on the Centers for Disease Control (CDC) criteria. All patients met Class IV criteria of the CDC [10]. Infectious diseases indicative of AIDS prior to ICU admission included: oropharyngeal candidiasis in eight cases: oesophageal candidiasis in one case; cerebral toxoplasmosis in one case; pulmonary tuberculosis in two cases; cutaneous Herpes simplex in two cases; and diarrhoea due to Cryptosporidia in one case. No patient with PCP had received prophylaxis against it. Patients admitted to our unit after 1988 and previously controlled in the Infectious Disease Unit, received antiretroviral drugs. Patients were divided into two groups depending on whether they were survivors or not.

Antibiotic therapy against Pneumocystis carinii included i.v. trimethoprim/sulphamethoxazole (TMP/SMZ), the maximal dosage for TMP was $20 \mathrm{mg} \cdot \mathrm{kg}^{-1}$ q.d., and for SMZ dosage $100 \mathrm{mg} \cdot \mathrm{kg}^{-1}$ q.d., in divided doses; or, i.v. pentamidine $\left(4 \mathrm{mg} \cdot \mathrm{kg}^{-1}\right.$ q.d.) according to the decision of the attending physician. After 1987, corticosteroids were routinely administered at the dosage of $1 \mathrm{mg} \cdot \mathrm{kg}^{-1}$ $q . d$. of methylprednisolone for 3 days. The dosage was later gradually reduced.

\section{Study variables}

The following variables were recorded: age; gender; AIDS risk factors; time course from hospital to ICU admission; and years since diagnosis of human immunodeficiency virus (HIV) antibodies. Leucocyte, lymphocyte and CD4+ counts, serum LDH, cholesterol, total proteins, albumin, creatinine and Simplified Acute Physiology Score (SAPS) were recorded upon ICU admission. The standardized and validated technique for CD4+ counting was not introduced in our Institution until 1988, since before that date antiretroviral treatment was not authorized in Spain. Therefore, we only report values from 18 patients belonging to the period after $1988(n=18)$.

Time course from ICU admission to mechanical ventilation (MV) was assessed. The era of admission (before or after 1987) and the presence or absence of corticosteroid therapy were registered. All the following variables were registered before admission to ICU, at admission to ICU, after $\mathrm{MV}$ institution, with maximal $F \mathrm{I}, \mathrm{O}_{2}$ and with maximal positive end-expiratory pressure (PEEP), and before death: $\mathrm{pH} ; \mathrm{Pa}_{2} \mathrm{O}_{2}$; arterial carbon dioxide tension
$\left(P \mathrm{a}, \mathrm{CO}_{2}\right) ; \mathrm{Pa}, \mathrm{O}_{2} / F \mathrm{I}, \mathrm{O}_{2}$ ratio, alveolar to arterial difference in oxygen tension $\left(\mathrm{A}-\mathrm{a} P \mathrm{O}_{2}\right)$ (calculated according to a standard formula [11]); PEEP; duration (hours) of maximal $\mathrm{FI}_{\mathrm{I}} \mathrm{O}_{2}$; duration (hours) of maximal PEEP; $\mathrm{Pa}, \mathrm{O}_{2} /$ alveolar oxygen tension $\left(\mathrm{PA}, \mathrm{O}_{2}\right)$ ratio; base deficit and/or base excess. The presence or absence of adult respiratory distress syndrome (ARDS) during ICU stay was also registered [12]. Diagnosis of ARDS was established by using the score described by MURRAY et al. [12] (>2.5). Since this definition of ARDS was not published until 1988, this variable was retrospectively recorded. Survivors were followed until death or last hospital control.

\section{Microbiological methods}

Bronchoalveolar lavage (BAL) was performed in 30 $(71 \%)$ cases, autopsy in $14(33 \%)$ and BAL together with protected specimen brush (PSB) (BFW 1.0/70/90; Meditech Inc., Water-town, MA, USA) in 24 (57\%). All these samples were retrieved by means of a fibreoptic bronchoscope (Olympus BFT3R, New Hyde Park, NY, USA) exclusively used for HIV-infected patients. Invasive techniques were carried out based on the decision of the attending clinician not involved in the study. BAL was performed using three aliquots of sterile $0.9 \%$ sodium chloride solution (50 mL each) instilled and subsequently aspirated. The lavage was performed in the middle lobe or lingula. The fluid obtained was pooled and divided into two: half of it was for microbiological cultures, and the other half was centrifuged $(500 \times \mathrm{g}, 10 \mathrm{~min})$ and the cell pellet was resuspended in phosphate-buffer solution. Smears were obtained by cytocentrifugation $(500 \mathrm{rpm}$, $10 \mathrm{~min}$ ) (Cytopsin, Shandon), stained by the Papanicolaou, Ziehl-Neelsen, Giemsa, periodic acid-Schiff (PAS), haematoxylin and eosin, Perls' and Grocott methenaminesilver methods, and examined for the presence of fungal hyphae and yeasts, as well as for Pneumocystis carinii, viral inclusion bodies, malignant cells and haemosiderinladen macrophages.

The diagnosis of cytomegalovirus was only considered if cytopathic changes were found in BAL samples or on histopathological examination at autopsy. PSB samples were retrieved following methods described previously [13]. Serial dilutions of BAL and PSB samples were prepared to obtain final concentrations of $1 / 10,1 / 100$ and 1/1000. Diluted and undiluted specimens were inoculated into the next media: blood-agar, Wilkins-Chalgren, chocolate-agar, BCYE- $\alpha$, and fungal media. Staining for Legionella pneumophila using the direct fluorescent antibody technique was performed. All cultures were incubated at $37^{\circ} \mathrm{C}$ under aerobic and anaerobic conditions and in a $\mathrm{CO}_{2}$-enriched atmosphere. If negative, they were discarded after 5 days for bacteria, and after 4 weeks for fungi. In each case, blood cultures were prepared for bacteria and fungi. Serological tests for respiratory virus (influenza, parainfluenza, adenovirus, respiratory syncytial virus), Mycoplasma pneumoniae, and Legionella pneumophila were also performed. For serological studies, one blood specimen was obtained at the time of the diagnosis and, when possible, another specimen was taken 2 weeks later. 


\section{Statistical analysis}

For comparison between survivors and nonsurvivors, we used the unpaired t-test and the Mann-Whitney test for continuous variables and the chi-squared test (Fisher's exact test when needed) for discrete data. The MantelHaenzel statistics, the levels of significance, the relative risks and their confidence intervals were calculated using the EPIinfo software [14].

For multivariate analysis, a stepwise logistic regression technique was applied, as described by Cox [15]. Pitfalls associated with this analysis were avoided as described by CONCATO et al. [16]; special care was taken to avoid overfitting: a model estimating the relative risk of death (yes/no) adjusted for the presence of PCP (yes/no); MV (yes/no); interval between hospital to ICU admission ( $\geq 3$ or $<3$ days); $P \mathrm{a}, \mathrm{O}_{2} / F \mathrm{I}, \mathrm{O}_{2}$ at hospital admission ( $\leq 20$ or $>20 \mathrm{kPa}$ ); and corticosteroid therapy (yes/no) was fit. Each variable included in the multivariate analysis was coded " 0 " for absence of the event and " 1 " for presence. These variables were selected because there was imbalance in the univariate analysis or they were considered clinically relevant (e.g: corticosteroid therapy). Interactions were tested in the model; variables with association between each other were not included in the analysis. Colinearity was assessed by means of a correlation matrix. No factors in the model correlated. As for influential observations, no patients with outlier values in any variable were detected. A stepforward approach was used, with 0.05 as a limit for entering or removing new terms.

The survival probability curves were calculated according to standard methods. Variable related to the time interval from ICU discharge to death was analysed by survival methods, including Kaplan-Meier estimate and log-rank test [15]. The "0" time interval was considered as the time of discharge from the ICU. Data were censored at 400 days. All p-values reported are two-tailed.

\section{Results}

Forty two AIDS patients were enrolled into the study. Nineteen (45\%) were survivors and $23(55 \%)$ were non-

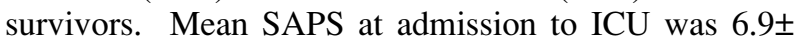
4.4 (SD). All patients were admitted because of acute respiratory failure $\left(\mathrm{Pa}_{\mathrm{a}} \mathrm{O}_{2} / \mathrm{FI}_{1} \mathrm{O}_{2}\right.$ ratio at hospital admission $19 \pm 14 \mathrm{kPa}$ ) and diffuse pulmonary infiltrates. Twenty nine $(69 \%)$ patients required MV. Twenty eight $(67 \%)$ patients had PCP, which was the first episode. The main characteristics of the population are summarized in table 1 . Mean CD4+ counts for the survivors $(n=11)$ was $0.11 \pm 0.13$ $\times 10^{9}$ cells $\cdot \mathrm{L}^{-1}$ (reference values of our laboratory $0.8-1.2$ $\times 10^{9}$ cells $\cdot \mathrm{L}^{-1}$ ), and $0.08 \pm 0.11 \times 10^{9}$ cells $\cdot \mathrm{L}^{-1}$ for the nonsurvivors $(\mathrm{n}=7)(\mathrm{NS})$.

\section{Microbiology}

The microorganisms isolated are shown in table 2 . Diagnosis of Pneumocystis carinii was achieved via microscopic examination of BAL fluid in 28 cases and
Table 1. - Main characteristics of the study population at ICCU admission $(n=42)$

\begin{tabular}{|c|c|}
\hline Age yrs & $37 \pm 12$ \\
\hline Gender $(\mathrm{M} / \mathrm{F})$ & $35 / 7$ \\
\hline \multicolumn{2}{|l|}{ Risk factors } \\
\hline i.v. drug abusers & $14(33)$ \\
\hline Homosexuals & $16(38)$ \\
\hline Others & $12(28)$ \\
\hline \multicolumn{2}{|l|}{ Interval from hospital } \\
\hline Time since diagnosis of HIV antibodies yrs & $1.1 \pm 2$ \\
\hline MV requirement $\quad \mathrm{n}(\%)$ & $29(69)$ \\
\hline Interval from ICU admission to MV days & $2.9 \pm 4.2$ \\
\hline Pneumocystis carinii pneumonia n (\%) & $28(67)$ \\
\hline $\mathrm{Pa}, \mathrm{O}_{2} / F \mathrm{I}, \mathrm{O}_{2}$ at hospital admission $\mathrm{kPa}$ & $19 \pm 14$ \\
\hline$P \mathrm{~A}-\mathrm{a}, \mathrm{O}_{2} \quad \mathrm{kPa}$ & $43 \pm 22$ \\
\hline SAPS & $6.9 \pm 4.4$ \\
\hline Leucocytes $\times 10^{9} \cdot \mathrm{L}^{-1}$ & $6.3 \pm 3.9$ \\
\hline Lymphocytes $\times 10^{9} \cdot \mathrm{L}^{-1}$ & $0.6 \pm 0.5$ \\
\hline $\mathrm{CD} 4+\quad \times 10^{9} \cdot \mathrm{L}^{-1} \quad(\mathrm{n}=18)$ & $0.10 \pm 0.11$ \\
\hline $\mathrm{LDH} \quad \mu \mathrm{kat} \cdot \mathrm{L}^{-1}$ & $21.6 \pm 9.2$ \\
\hline Cholesterol $\mathrm{mol} \cdot \mathrm{L}^{-1}$ & $3.4 \pm 1.3$ \\
\hline $\mathrm{mg} \cdot \mathrm{dL}^{-1}$ & $132 \pm 50$ \\
\hline Proteins $\mathrm{g} \cdot \mathrm{L}^{-1}$ & $58 \pm 7$ \\
\hline Albumin $g \cdot \mathrm{L}^{-1}$ & $24 \pm 6$ \\
\hline Creatinine $\mathrm{mmol} \cdot \mathrm{L}^{-1}$ & $103 \pm 60$ \\
\hline
\end{tabular}

Values are presented as mean \pm SD. ICU: Intensive Care Unit; HIV: human immunodeficiency virus; SAPS: Simplified Acute Physiology Score; MV: mechanical ventilation; M: male; F: female; $\mathrm{LDH}$ : lactate dehydrogenase; $\mathrm{Pa}_{\mathrm{a}} \mathrm{O}_{2}$ : arterial oxygen tension; $F \mathrm{I}_{1} \mathrm{O}_{2}$ : inspiratory oxygen fraction; $\mathrm{PA}-\mathrm{a}, \mathrm{O}_{2}$ : alveolar to arterial difference in oxygen tension.

confirmed by autopsy in 10 cases. Cytomegalovirus pneumonia was diagnosed in five cases $(12 \%)$. The comparison of in vivo diagnoses versus necropsy diagnoses is shown in table 3 . Five cases infected with cytomegalovirus (three pulmonary infections, one renal and one adrenal) and one with Pneumocystis carinii were diagnosed based on postmortem findings only. Thirteen $(31 \%)$ patients had polymicrobial aetiologies of their pulmonary infiltrates. Seven out of 28 cases $(25 \%)$ of PCP had other concomitant pulmonary infections. Blood cultures and serologies were always negative.

Table 2. - Microorganisms isolated from the 42 patients

\begin{tabular}{lrrc}
\hline Microorganism isolated & \multicolumn{2}{c}{ Cases } & Diagnostic \\
& \multicolumn{1}{c}{ m } & $\%$ & method* \\
\hline P. carinii alone & 21 & $(50)$ & BAL (except 1 case) \\
P. carinii + M. tuberculosis & 1 & $(2)$ & BAL \\
P. carinii + Cytomegalovirus & 5 & $(12)$ & BAL and necropsy \\
P. carinii + P. aeruginosa & 1 & $(2)$ & BAL \\
Haemophilus influenzae & 1 & $(2)$ & BAL \\
Mycobacterium kansasii & 1 & $(2)$ & BAL \\
Streptococcus pneumoniae & 1 & $(2)$ & BAL + PSB \\
Negative cultures & 11 & $(26)$ & - \\
\hline
\end{tabular}

*: one case was only diagnosed by autopsy findings, in addition autopsy findings confirmed the diagnosis achieved by BAL in 10 of the cases previously diagnosed by BAL. P. carinii: Pneumocystis carinii; $M$. tuberculosis: Mycobacterium tuberculosis; P. aeruginosa: Pseudomonas aeruginosa. BAL: bronchoalveolar lavage; PSB: protected specimen brush. 
Table 3. - Comparison of in vivo diagnosis versus necropsy studies

\begin{tabular}{rll}
\hline Pt & In vivo & Necropsy \\
\hline 1 & PCP & PCP \\
2 & PCP & PCP, pulmonary cytomegalovirus \\
3 & Bacterial pneumonia & Acute lung injury \\
4 & Bacterial pneumonia & PCP, liver cirrhosis, diffuse alveolar damage \\
5 & PCP & PCP, cutaneous Kaposi's sarcoma \\
6 & PCP & Pulmonary condensation, cerebral oedema \\
7 & PCP & Bacteria pneumonia \\
8 & PCP & PCP, pulmonary cytomegalovirus, diffuse alveolar damage \\
9 & PCP, cytomegalovirus & Pulmonary infarction, pulmonary thromboembolism, alcoholic hepatitis \\
10 & PCP & PCP, cutaneous Kaposi's sarcoma, suprarenal cytomegalovirus, pleural effusion \\
11 & PCP, pulmonary TB & PCP, diffuse alveolar damage, hepatic cirrhosis \\
12 & PCP & PCP, diffuse alveolar damage, cytomegalovirus, adrenalitis, steatosis, Kaposi's sarcoma \\
13 & PCP & PCP, diffuse alveolar damage, bilateral bacterial bronchopneumonia \\
14 & PCP & PCP, pulmonary cytomegalovirus \\
\hline
\end{tabular}

PCP: Pneumocystis carinii pneumonia; TB: tuberculosis; Pt: patient.

\section{Prognostic factors influencing the outcome}

Univariate analysis. Table 4 shows the relative risks of death among survivors and nonsurvivors using the univariate analysis. The following variables proved to be statistically significant: requirement of MV; MV period ( $>6 \mathrm{~h}$ ) while breathing $100 \% \mathrm{O}_{2}$; presence or absence of ARDS; $\mathrm{pH}$ before death $(\leq 7.35)$; and, interval between hospital to ICU admission ( $<3$ days). The following variables proved to be statistically nonsignificant: $\mathrm{Pa}, \mathrm{O}_{2} / F \mathrm{I}, \mathrm{O}_{2}$ ratio at hospital admission; presence or absence of PCP; corticosteroid therapy (yes/no); era of admission (before/ after 1987); polymicrobial aetiology (yes/no); interval since diagnosis of HIV antibodies; age; serum cholesterol; LDH; creatinine at ICU admission; SAPS at ICU admission; interval between ICU admission to initiation of MV; serum albumin; leucocyte count at ICU admission; and $\mathrm{A}-\mathrm{a} \mathrm{PO}_{2}$ at admission to ICU.
Twenty nine patients (69\%) needed MV versus 13 (31\%) who required other types of ventilatory support and oxygen delivery, such as continuous positive airway pressure (CPAP), Venturi masks, or masks with reservoirs. There were more nonsurvivors among patients needing MV (21 out of $29,(72 \%)$ ) versus those who did not require it (2 out of $13(15 \%) ; \mathrm{p}=0.0019)$. Patients with MV periods $>6 \mathrm{~h}$ while breathing $100 \% \mathrm{O}_{2}$ had a three times greater risk of not surviving (16 out of $18(89 \%)$ versus 4 out of $13(31 \%)$ ). Likewise, nonsurvivors were more frequent among patients with ARDS (13 out of 15 (87\%)) versus patients without ARDS (6 out of $20(30 \%)$; $\mathrm{p}=0.0028)$. Patients with arterial $\mathrm{pH}<7.35$ had twice the risk of dying (8 out of $9(89 \%)$ versus 9 out of $20(45 \%)$ ).

Although not statistically significant, the risk of death was 2.2 times greater in patients in whom the $\mathrm{Pa}, \mathrm{O}_{2} / \mathrm{FI}, \mathrm{O}_{2}$ ratio was $<20 \mathrm{kPa}$ at admission to ICU (15 out of 22 $(68 \%)$ versus 4 out of $13(31 \%)$; $=0.07)$. Also, the risk

Table 4. - Relative risks of death among survivors and nonsurvivors in descending order

\begin{tabular}{|c|c|c|c|c|c|c|c|}
\hline & \multicolumn{2}{|c|}{ Nonsurvivors } & \multicolumn{2}{|c|}{ Survivors* } & \multirow[t]{2}{*}{$\mathrm{RR}$} & \multirow[t]{2}{*}{$(95 \% \mathrm{CI})$} & \multirow[t]{2}{*}{$\mathrm{p}$-value } \\
\hline & $\mathrm{n}$ & $(\%)$ & $\mathrm{n}$ & $(\%)$ & & & \\
\hline Mechanical ventilation & 21 & (72) & 8 & (28) & 4.7 & $(1.3-17.2)$ & 0.0019 \\
\hline MV period $(>6 \mathrm{~h})$ with $F_{\mathrm{I}, \mathrm{O}_{2}}=1.0$ & 16 & (89) & 2 & (11) & 2.9 & $(1.3-6.6)$ & 0.002 \\
\hline Adult respiratory distress syndrome & 13 & (87) & 2 & (13) & 2.9 & $(1.4-5.8)$ & 0.0028 \\
\hline 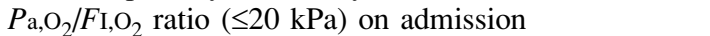 & 15 & (68) & 7 & (32) & 2.2 & $(0.9-5.2)$ & 0.07 \\
\hline Arterial blood pH $(\leq 7.35)$ & 8 & (89) & 1 & (11) & 1.9 & $(1.1-3.3)$ & 0.04 \\
\hline Interval between hospital to ICU admission ( $<3$ days) & 10 & $(45)$ & 12 & (55) & 1.8 & $(0.8-4.53)$ & 0.0539 \\
\hline Pneumocystis carinii pneumonia & 18 & (64) & 10 & (36) & 1.8 & $(0.85-3.8)$ & 0.08 \\
\hline Corticosteroid therapy & 11 & (73) & 4 & (27) & 1.65 & $(0.98-2.78)$ & 0.13 \\
\hline Era of admission (before 1987) & 11 & (73) & 4 & (27) & 1.65 & $(0.98-2.78)$ & 0.13 \\
\hline Polymicrobial aetiology & 10 & (77) & 3 & (23) & 1.26 & $(0.78-2.02)$ & 0.45 \\
\hline Months since diagnosis of HIV ( $\leq 6$ months) & 16 & (64) & 9 & (36) & 1.4 & $(0.7-2.6)$ & 0.29 \\
\hline Age $(\geq 35$ yrs $)$ & 14 & $(58)$ & 10 & $(42)$ & 1.17 & $(0.66-2.07)$ & 0.59 \\
\hline Cholesterol $\geq 5 \mathrm{mmol} \cdot \mathrm{L}^{-1}\left(\geq 200 \mathrm{mg} \cdot \mathrm{dL}^{-1}\right)$ & 21 & $(55)$ & 17 & (45) & 1.1 & $(0.4-3.06)$ & 0.9 \\
\hline Lactate dehydrogenase $\left(\geq 24 \mu \mathrm{kat} \cdot \mathrm{L}^{-1}\right)$ & 12 & $(52)$ & 11 & (48) & 0.9 & $(0.4-1.6)$ & 0.7 \\
\hline Creatinine $\left(\geq 88 \mathrm{mmol} \cdot \mathrm{L}^{-1}\right)$ & 13 & (54) & 11 & (46) & 0.9 & $(0.5-1.5)$ & 0.76 \\
\hline SAPS $(\geq 12)$ & 10 & $(45)$ & 12 & $(55)$ & 0.72 & $(0.41-1.28)$ & 0.41 \\
\hline Interval ICU admission to MV ( $\geq 4$ days) & 5 & (83) & 1 & (17) & 0.69 & $(0.41-1.15)$ & 0.36 \\
\hline Serum albumin $\left(<25 \mathrm{~g} \cdot \mathrm{L}^{-1}\right)$ & 11 & $(85)$ & 2 & (15) & 0.69 & $(0.3-1.51)$ & 0.4 \\
\hline Leucocyte count $\left(\leq 4.0 \times 10^{9}\right.$ cells $\left.\cdot \mathrm{L}^{-1}\right)$ & 5 & $(38)$ & 8 & $(62)$ & 0.62 & $(0.29-1.3)$ & 0.2 \\
\hline$P \mathrm{~A}-\mathrm{a}, \mathrm{O}_{2}$ on admisssion to ICU $(\geq 40 \mathrm{kPa})$ & 6 & (37) & 10 & $(63)$ & 0.5 & $(0.2-1.1)$ & 0.1 \\
\hline
\end{tabular}

Patients were classified into "high" or "low" risk based upon an arbitrary cut-off value for quantitative variables. RR: relative risk; 95\% CI: 95\% confidence interval. For further abbreviations see legend to table 1 . 
of death was 1.8 times higher when the interval between hospital to ICU admission was greater than 3 days (13 out of $17(76 \%)$ versus 10 out of $22(45 \%) ; p=0.0539)$. There was a trend for a worse outcome for patients having PCP (18 out of 28 (64\%) versus 5 out of 14 (36\%); $\mathrm{p}=0.08$ ) compared to the remaining aetiologies (including patients without aetiological diagnosis).

\section{Multivariate analysis}

The multivariate analysis (stepwise logistic regression) after adjusting for the presence of PCP, the requirement of MV, interval between hospital and ICU admission, $\mathrm{Pa}_{2} \mathrm{O}_{2} / \mathrm{FI}_{\mathrm{I}} \mathrm{O}_{2}$ ratio at hospital admission, and treatment with corticosteroids, demonstrated that the presence of PCP (relative risk (RR): $3.2 ; 95 \%$ confidence interval $(95 \%$

a)

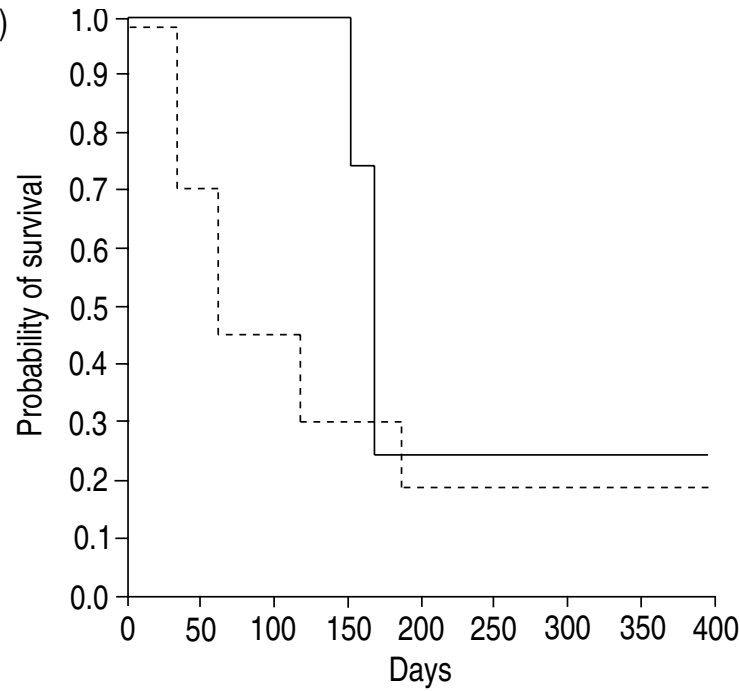

b)

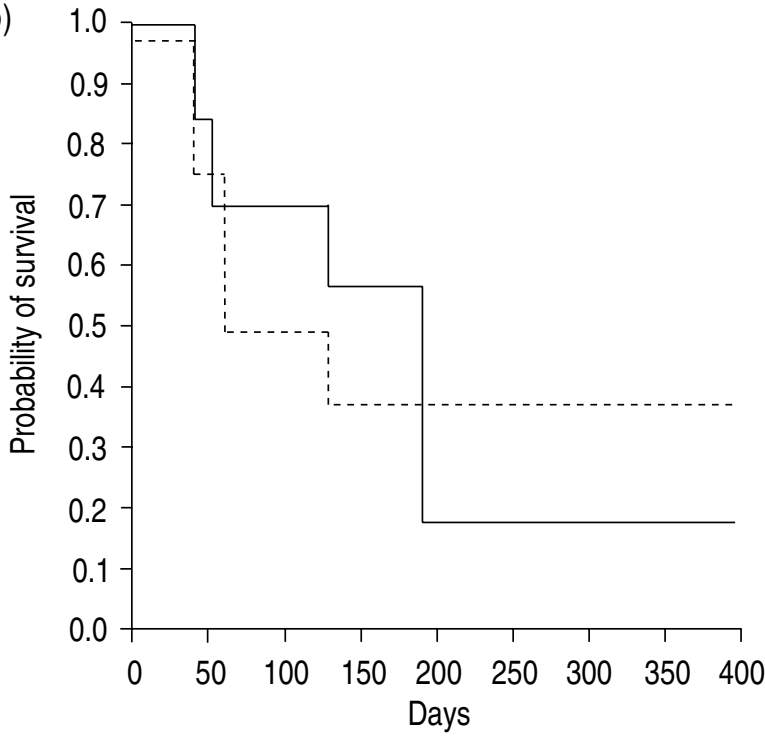

Fig. 1. - Kaplan-Meier estimates of probability to survive: a) in patients with (----) and without (- Pneumocystis carinii pneumonia (PCP); and, b) in patients with (------) and without (mechanical ventilation $(\mathrm{MV}), \mathrm{p}=0.25$ for both plots. a) Median survival time for PCP and non-PCP was 49 and 154 days, respectively ( $\mathrm{p}=$ $0.014)$. b) Median survival time for mechanically ventilated patients and non-mechanically-ventilated was 112 and 154 days, respectively (Ns).
$\mathrm{CI}): 2.4-26 ; \mathrm{p}=0.005)$, and the requirement for $\mathrm{MV}(\mathrm{RR}$ 2.6; 95\% CI: $1.3-14.5 ; \mathrm{p}=0.018)$ were independent factors significantly related with death.

\section{Follow-up of survivors}

Nineteen (45\%) patients were discharged alive from the ICU. When analysing patients who had PCP versus those who had other infectious or unknown aetiologies of respiratory failure, initial differences $(\mathrm{p}=0.014)$ were shown in the probability to survive among both populations (median survival times were 49 days for PCP population versus 154 days for other aetiologies). These probabilities lost their significance after the 170 day survival time $(p=0.25)$. Again survival plots were compared for patients with and without MV. No differences were shown when comparing both survival curves. Median survival times were 112 days for patients with $\mathrm{MV}$ and 154 days for those without MV (fig. 1).

\section{Discussion}

The main findings of the present study show that AIDS patients presenting with pulmonary infiltrates and severe acute respiratory failure have a high mortality rate (23 out of $42(55 \%))$. This mortality rate increased markedly (72\%) when MV was required. The presence of PCP and the requirement of MV were the main factors related to prognosis. Patients with PCP showed a poor outcome after ICU discharge, with a median survival period of 49 days. In our series, we found that Cytomegalovirus pneumonia is not an uncommon aetiological agent, causing severe respiratory failure in AIDS and being underdiagnosed during life.

Whilst respiratory failure is the most common cause of ICU admission for AIDS patients [17], the admission to ICU of these patients has been a controversial issue. The first reports indicated that this population had a very low ICU survival rate; suggesting, therefore, the avoidance of ICU admission for this type of patient [18]. However, these opinions have recently been challenged when confirming better survival rates of $40-50 \%[3,8$, $9,18]$. Most of these views were based upon patients presenting with the first episode of PCP. In our study, we obtained a survival rate of around $45 \%$ for the whole population and $36 \%$ for patients with PCP. When examining outcomes before and after 1987, we found a trend towards a better short-term ICU outcome after 1987 (56\%) versus $(27 \%)$ before 1987 . Thus, our results agree with those reported in the literature [18, 19]. We think that the short-term prognosis of AIDS patients with acute severe respiratory failure is not so poor as originally expected and is much better when compared to other immunosuppressed populations, such as bone marrow transplant patients with acute respiratory failure [20].

The better prognosis of AIDS patients with acute respiratory failure in the recent era seems to be related to several factors, such as: the use of corticosteroids for PCP [21]; an improvement in the learning process of the disease and its complications; a better nutritional status 
of these patients; better critical care management [9]; and perhaps an adequate prophylaxis against PCP, although none of our patients had received it. Despite the improvement of short-term prognosis of these patients, the survival curves after ICU discharge in our study are quite disappointing - in terms of long-term outcome - for patients with PCP (median survival time 49 days). These results suggest, therefore, that the admission of patients with PCP to ICU needs to be seriously reconsidered in terms of life-expectancy.

The presence of PCP was an independent prognostic factor for mortality in this study. These results may be partially biased by the cases in which cytomegalovirus was concomitantly isolated and all died; although, polymicrobial associations proved to be nonsignificant in the univariate analysis of prognosis. However, a recent article from BozzeTte et al. [22] demonstrated that neither cytomegalovirus nor PCP were predictors of mortality in a multivariate analysis. The discrepancies with our study may be explained by differences in populations studied.

Several prognostic factors have been detected in AIDS patients admitted to ICU because of respiratory failure. In particular, these have been studied in patients with PCP $[3,9,19,23,24]$. Some studies showing an improved outcome [23] were unable to find predictors. Others have found that prognosis is directly related to the severity of acute respiratory failure. In the present study, we found that the major determinant of prognosis in AIDS patients admitted to ICU with acute respiratory failure was the requirement of MV. Other related factors, such as the presence of ARDS, and breathing $100 \%$ oxygen for more than $6 \mathrm{~h}$ proved to be significant in the univariate analysis.

By contrast, we have recently shown that the outcome of general ICU admitted populations is not related to the severity of the respiratory failure within the first $48 \mathrm{~h}$ of ICU admission [25]. Conceivably, this finding denotes that the pathophysiology of acute respiratory failure in AIDS patients, particularly when caused by Pneumocystis carinii, needs to be regarded as a "unique" situation. There is evidence that PCP by itself limits the alveolar endocapillary diffusion for $\mathrm{O}_{2}$, possibly related to a large reduction in the membrane diffusing capacity of the alveoli [26]. Direct evidence confirming our hypothesis comes from one study that found a correlation between the severity of interstitial oedema and the prognosis of the patients with PCP [7].

Other factors related to a better outcome referred to in the literature are: treatment with corticosteroids; decrease in serum lactate; high serum albumin and cholesterol levels; shorter duration of symptoms before admission to ICU; absence of metabolic acidaemia; duration of known seropositivity for HIV antigen; the interval between the onset of medical treatment and that of $\mathrm{MV}$; and the immunological status of patients as measured by the CD4+ levels [3, 19, 23]. Some of these factors were not specifically examined in this study, and others were not significant except for the presence of metabolic acidosis, found to be significant in univariate analysis. As regards CD4+ counts, we did not find differences when comparing survivors and nonsurvivors, although these counts were available in only 18 patients. This finding has also recently been reported in a series of $\mathrm{PCP}$ patients requiring ICU treatment [27].

A possible pitfall of this study is the lack of information regarding the prior management of the patients before ICU admission, depending mainly on out-patient care physicians. However, we could evaluate the interval between hospital to ICU admission. In the univariate analysis, patients in whom this period was higher than 3 days had a poorer prognosis compared to those admitted to the ICU before this period.

Another finding in our study was the relatively high prevalence of cytomegalovirus infection in patients who died $(22 \%)$. In the present study, the diagnosis of cytomegalovirus during life was infrequent. This may be due to the poor sensitivity of the diagnostic method used (detection of cytopathic effect in cells retrieved from BAL fluid). Other methods, such as immunocytochemical staining and viral culture, appear to be more sensitive [28]. Although cytomegalovirus pneumonia was recognized early as a true pathogen for AIDS patients [29], the finding of this microorganism in the absence of histological evidence of cytopathic abnormalities in the lung is common and has caused great confusion between the concepts of infection and disease. For instance, at least two studies have suggested that the detection of cytomegalovirus does not imply an indication for antiviral treatment in noncritically ill patients, particularly when Pneumocystis carinii is concomitantly isolated [22, 30]. In our series, cytomegalovirus infection has been demonstrated at autopsy, but not in vivo, on five occasions (three lung infections, one renal, and one adrenal) indicating that this viral infectious complication has to be taken into account in severely critically-ill AIDS patients.

The relatively low incidence of bacterial pneumonia $(16 \%)$ in our population could be explained by the selective features of the study population, that mainly comprised AIDS patients with diffuse pulmonary infiltrates and severe respiratory failure, in whom opportunistic infections are much more common. However, prior information from our group [31] demonstrated that the overall incidence of bacteria pneumonia in HIV patients with pulmonary infiltrates is $21 \%$.

In summary, although the ICU survival rate in this study was reasonable $55 \%$ for the whole population and $36 \%$ for $P$. carinii pneumonia patients) the poor outcome after ICU discharge, in particular for $P$. carinii pneumonia patients, deserves the reassessment of ICU admission criteria for this type of AIDS population.

\section{References}

1. Centers for Disease Control, US Department of Health and Human Services. Classification system for human T-lymphotropic virus type III/lymphadenopathy-associated virus infections. Ann Intern Med 1986; 105: 234 237.

2. Murray JF, Felton CP, Garay SM, et al. Pulmonary complications of the acquired immunodeficiency syndrome. Report of a National Heart, Lung and Blood Institute Workshop. N Engl J Med 1984; 310: 1682-1688. 
3. El-Sadr W, Simberkoff MS. Survival and prognostic factors in severe Pneumocystis carinii pneumonia requiring mechanical ventilation. Am Rev Respir Dis 1988; 137: 1264-1267.

4. Kovacs JA, Hiemenz JW, Macher AM, Stover D, Murray HW, Shelhamer J. Pneumocystis carinii pneumonia: a comparison between patients with the acquired immunodeficiency syndrome and patients with other immunodeficiencies. Ann Intern Med 1984; 100: 663-671.

5. Benson CA, Spear J, Hines D, Pottage JC, Kessler HA, Trenholme GM. Combined APACHE II score and serum lactate dehydrogenase as predictors of in-hospital mortality caused by first episode Pneumocystis carinii pneumonia in patients with acquired immunodeficiency syndrome. Am Rev Respir Dis 1991; 144: 319-323.

6. Garay SM, Greene J. Prognostic indicators in the initial presentation of Pneumocystis carinii pneumonia. Chest 1989; 95: 769-772.

7. Brenner M, Ognibene FP, Lack EE, et al. Prognostic factors and life expectancy of patients with acquired immunodeficiency syndrome and Pneumocystis carinii pneumonia. Am Rev Respir Dis 1987; 138: 1119-1126.

8. Freidman Y, Franklin C, Rackow EC, Weil MH. Improved survival in patients with AIDS, Pneumocystis carinii pneumonia, and severe respiratory failure. Chest 1989; 96: 862-866.

9. Wachter RM, Russi MB, Bloch DA, Hopewell PC, Luce JM. Pneumocystis carinii pneumonia and respiratory failure in AIDS. Improved outcomes and increased use of intensive care units. Am Rev Respir Dis 1991; 143: 251-256.

10. Centers for Disease Control. Update on acquired immune deficiency syndrome (AIDS) - United States. MMWR 1982; 31: 507-511.

11. Otis AB. Quantitative relationships in steady-state gas exchange. In: Fenn WO, Rahn H, eds. The Handbook of Physiology. Section 3. Respiration. Vol. 1. American Physiological Society. Baltimore, William and Wilkins Co. 1964.

12. Murray JF, Mathay MA, Luce JM, Flick MR. An expanded definition of the adult respiratory distress syndrome. Am Rev Respir Dis 1988; 138: 720-723.

13. Torres A, Puig de la Bellacasa J, Xaubet A, et al. Diagnostic value of quantitative cultures of bronchoalveolar lavage and telescoping plugged catheters in mechanically- ventilated patients with bacterial pneumonia. $\mathrm{Am}$ Rev Respir Dis 1989; 140: 306-310.

14. Dean J, Dean A, Burton A, Dicker A. EPIinfo, version 5.01. CDC, Epidemiology Program Office, Atlanta. Georgia, April 1990.

15. Cox DR. Regression models and life-tables. J R Stat Soc (B) 1972; 34: 187-220.

16. Concato J, Feinstein AR, Holford TR. The risk of determining risk with multivariable models. Ann Intern Med 1993; 118: 201-210.

17. Rogers PL, Lane HC, Henderson DK, Parrillo J, Masur $\mathrm{H}$. Admission of AIDS patients to a medical Intensive Care Unit: causes and outcome. Crit Care Med 1989; 17: 113-117.

18. Wachter RM, Luce JM, Turner J, Volberding P, Hopewell PC. Intensive care of patients with the acquired immunodeficiency syndrome: outcome and changing patterns of utilization. Am Rev Respir Dis 1986; 134: 891896.

19. Staikowsky F, Lafon B, Guidet B, Denis M, Mayaud C, Offenstadt G. Mechanical ventilation for Pneumocystis carinii pneumonia in patients with the acquired immunodeficiency syndrome. Is the prognosis really improved? Chest 1993; 104: 756-762.

20. Faber-Langendoen K, Caplan AL, McGlave PB. Survival of adult bone marrow transplant patients receiving mechanical ventilation: a case for restricted use. Bone Marrow Transplant 1993; 12: 501-507.

21. Gagnon S, Boota AM, Fischl MA, Baier H, Kirksey OW, La Voie L. Corticosteroids as adjunctive therapy for severe Pneumocystis carinii pneumonia in the acquired immunodeficiency syndrome: a double-blind, placebocontrolled trial. N Engl J Med 1990; 323: 1444-1450.

22. Bozzette SA, Arcia J, Bartok AE, et al. Impact of Pneumocystis carinii and Cytomegalovirus on the course and outcome of atypical pneumonia in advanced human immunodeficiency virus disease. J Infect Dis 1992; 165: 93-98.

23. Peruzzi WT, Skoutelis A, Shapiro BA, et al. Intensive Care Unit patients with acquired immunodeficiency syndrome and Pneumocystis carinii pneumonia; suggested predictors of hospital outcome. Crit Care Med 1991; 7: 892-900.

24. Efferen LS, Nadarajah D, Palat DS. Survival following mechanical ventilation for Pneumocystis carinii pneumonia in patients with the acquired immunodeficiency syndrome: A different perspective. Am J Med 1989; 87: 401-404.

25. Jiménez P, Torres A, Roca J, Cobos A, Rodriguez-Roisin R. Arterial oxygenation does not predict the outcome of patients with acute respiratory failure needing mechanical ventilation. Eur Respir J 1994; 7: 730-735.

26. Sankary RM, Turner J, Lipavsky AJ, Howes EL, Murray JF. Reversible alveolar-capillary block in patients with AIDS and Pneumocystis carinii pneumonia (PCP). Am Rev Respir Dis 1988; 137: 443-449.

27. Curtis JR, Greenberg DL, Hudson LD, Fisher LD, Krone MR, Collier AC. Changing use of intensive care for HIV-infected patients with Pneumocystis carinii pneumonia. Am J Respir Crit Care Med 1994; 150: 13051310.

28. Crawford SW, Bowden RA, Hackman RC, Gleaves CA, Meyers JD, Clark JG. Rapid detection of Cytomegalovirus pulmonary infection by bronchoalveolar lavage and centrifugation culture. Ann Intern Med 1988; 108: 180_ 185.

29. Murray JF, Garay SM, Hopewell PC, Milss J, Snider GL, Stover DE. Pulmonary complications of the acquired immunodeficiency syndrome: an update. Report of the Second National Heart, Lung, and Blood Institute Workshop. Am Rev Respir Dis 1987; 135: 504-509.

30. Jacobson MA, Mills J, Rush J, et al. Morbidity and mortality of patients with AIDS and first episode of Pneumocystis carinii pneumonia unaffected by concomitant pulmonary cytomegalovirus infection. Am Rev Respir Dis 1991; 144: 6-9.

31. Ferrer M, Torres A, Xaubet A, et al. Diagnostic value of telescoping plugged catheters in HIV-infected patients with pulmonary infiltrates. Chest 1992; 102: 76-83. 